\title{
SUSTENTABILIDADE: A PRODUÇÃO CIENTÍFICA BRASILEIRA ENTRE OS ANOS DE 2000 E 2009
}

\author{
Luciano Antonio Prates Junqueira \\ Doutor em Administração da Saúde pela Universidade de São Paulo - USP \\ Professor da Pontifícia Universidade Católica de São Paulo - PUC/SP \\ junq@pucsp.br
}

João Souto Maior

Mestrando em Administração de empresas Pontifícia Universidade Católica de São Paulo - PUC/SP jmaior@gmail.com

\section{Fabiana Pereira Pinheiro}

Mestranda em Administração de empresas Pontifícia Universidade Católica de São Paulo - PUC/SP fabianappinheiro@gmail.com

\section{RESUMO}

Este artigo tem por objetivo fazer um balanço da produção científica da área da administração de empresas sobre sustentabilidade, bem como verificar a sua temática predominante e quais os autores e as respectivas instituições de ensino e de pesquisa brasileiras que se destacam pelo volume de produções científicas publicadas assim como qual o perfil metodológico de tais produções. Para tanto, foi feita uma revisão sistemática e avaliação critica das publicações mais renomadas da área da Administração no Brasil do ano de 2000 até 2009, dentre elas a: Revista de Administração de Empresas (RAE), Revista de Administração Pública (RAP), Organizações \& Sociedade (O\&S), assim como os Anais do Encontro Anual da Associação Nacional de Pós-Graduação e Pesquisa em Administração (EnANPAD). Como resultado da pesquisa nota-se que o tema sustentabilidade ainda encontra-se em fase de evolução nas publicações pesquisadas e no EnANPAD. Foram analisados 106 artigos, sendo 27 nos periódicos e 79 no EnANPAD. A análise destes dados revela que o comportamento da produção científica analisada confirma as premissas do presente estudo, demonstrando que a sustentabilidade ainda desperta interesse comedido dos autores nacionais.

Palavras-chave: Pesquisa; Sustentabilidade; Desenvolvimento sustentável.

\section{SUSTAINABILITY: A BRAZILIAN SCIENTIFIC PRODUCTION BETWEEN THE YEARS 2000 AND 2009}

\begin{abstract}
This article aims to make a review of the business administration research contribution regarding sustainability. It also verifies what is the predominant thematic, the authors and research institutions that can be highlighted by the number of publications and used methodology. In order to achieve this, systematic review and critical evaluation were executed in the most relevant Brazilian scientific journals regarding business administration, between 2000 and 2009. Among them, Revista de Administração de Empresas (RAE), Revista de Administração Pública (RAP), Organizações \& Sociedade (O\&S) and Anais do Encontro Anual da Associação Nacional de Pós-Graduação e Pesquisa em Administração (EnANPAD). As the result of this research it is possible to perceive this topic stills in growth in the selected journals. 106 articles were analyzed, 79 from EnANPAD and 27 from RAE, RAP and O\&S. This analysis reveals the actual scientific production on this regarding and confirms the assumptions of this research, showing that this topic only represents moderate interest in the Brazilian research area.
\end{abstract}

Keywords: Research; Sustainability; Sustainable development. 


\section{INTRODUÇÃO}

Sabe-se que produção científica é dos elementos de maior importância no conjunto das atividades acadêmicas, dado que, através dela, é que o conhecimento desenvolvido no âmbito da universidade é difundido e democratizado. Em certo sentido, é também o que expressa o esforço institucional na atividade de pesquisa e a capacitação de seus quadros.

A produção científica deixa o espaço da universidade e se incorpora no que se poderia chamar de debate público, por meio da publicação de livros, de artigos em revistas e periódicos especializados, bem como por via de apresentações de resultados de pesquisas e/ou de estudos em fóruns nacionais e internacionais, normalmente difundidos sob a forma de anais. Nesses termos, realizar o balanço da produção cientifica sobre determinado tema objetiva não apenas identificar o que as universidades produzem, ou como suas pesquisas vêm sendo realizadas, mas também como tal produção se propaga para fora de seus muros e auxilia no sentido de organizar as idéias, possibilitar avanços e promover orientações seguras para a aplicação prática de novas conexões.

Claro, está que os balanços da produção do conhecimento científico podem ser críticos ou meramente analíticos, porém, em ambos os casos, partem da indagação sobre quais as principais características da produção sobre certo tema e, necessariamente, é realizada tendo como referência a matriz científica existente, considerando os dados dos pesquisadores, de suas instituições de origem e, principalmente, quanto às referências teórico-metodológicas que predominantemente utilizam. Trata-se, de toda forma, de um esforço para identificar a tendência dos produtos intelectuais.

O presente trabalho objetiva realizar o balanço analítico da produção do conhecimento sobre os aspectos ligados à sustentabilidade, tema que tem se revelado como de grande importância e premência para a sociedade contemporânea. Entretanto, a par do interesse crescente pela área, partese do pressuposto de que a produção científica a ela correspondente ainda encontra-se relativamente incipiente. Assim, ao se realizar o balanço da produção sobre o tema sustentabilidade, objetiva-se, concomitantemente, confirmar ou este pressuposto, bem como verificar como vem evoluindo o tratamento do tema e qual a contribuição da produção acadêmica (em seu estágio atual) para constituição de conhecimento relevante e aplicável em administração.

\section{SUSTENTABILIDADE: UM POUCO DA EVOLUÇÃO HISTÓRICA}

O tema sustentabilidade, gradativamente, deixou de se constituir em mera preocupação ou um discurso de poucos e, na última década e meia, tem sido recorrente e amplamente discutido nos meios acadêmico, empresarial e governamental e tomado parte importante da preocupação da sociedade civil, permitindo inúmeras interpretações e adaptações.

Antes mesmo de se expandir como movimento da sustentabilidade, os temas sociais e ambientais começam a ser debatidos no mundo corporativo e nas universidades sob a égide da Responsabilidade Social Empresarial, como nos Estados Unidos da América nos anos 1950. Nos anos 1960 e 70, catástrofes ambientais se avolumam, denotando a inabilidade do mundo em administrar o meio ambiente. O número de pessoas atingidas por catástrofes naturais dobrou a cada ano da década de 60 para a de 70, sendo que as mais diretamente ligadas à má administração do meio ambiente e do desenvolvimento - secas e inundações - foram as maiores causadoras de vítimas. Essas crises ambientais expõem a fragilidade da dimensão social da economia, incentivando iniciativas globais, a criação de organismos internacionais, e, consequentemente, os debates e a busca de soluções para os problemas.

Ainda anos 1960, o livro Primavera Silenciosa, da bióloga americana Rachel Carson, é lançado com grande sucesso e se torna um marco importante, pois nele a autora consegue expressar, à época, parte da inquietude de cientistas e estudiosos do mundo todo sobre a relação e interação entre as questões ambientais e a ação empresarial. Na década de 1970, o relatório Limites do Crescimento, publicado pelo Clube de Roma, deu origem a uma série de estudos, criando a linha de pesquisa da economia do meio ambiente. $\mathrm{O}$ debate começa a ganhar força e a ser denominado de desenvolvimento sustentável. Mais tarde, a partir de 1980, também passa a ser chamado de

Revista de Gestão Social e Ambiental - RGSA, São Paulo, v. 5, n. 3, p. 36-52, set./dez. 2011. 
Sustentabilidade, como denominado pela primeira vez por Lester Brown, fundador do Earth Policy Institute, organização sem fins lucrativos que trata de temas relacionados à sustentabilidade e autor de livros sobre a área, especialmente as questões do meio ambiente, como o Plano B 4.0 de 2010.

Dentre as iniciativas que marcam esse movimento, a Conferência das Nações Unidas sobre o Meio Ambiente Humano, realizada em Estocolmo, em 1972, é uma referência importante, embora a expressão sustentabilidade ou desenvolvimento sustentável ainda não fosse usada. Uma das grandes contribuições da conferência foi vincular a questão ambiental à social, tornando-se também um marco na aproximação com o movimento da Responsabilidade Social. Onze anos após, em 1983, é criada a Comissão Mundial sobre o Meio Ambiente e Desenvolvimento, estabelecida pela Organização das Nações Unidas, com objetivos de pensar uma agenda global para as mudanças contendo: i) estratégias ambientais de longo prazo para obter-se um desenvolvimento sustentável por volta dos anos 2000; ii) recomendações de formas de cooperação entre países em estágios diferentes de desenvolvimento; e iii) noções e esforços comuns para melhorias e proteção ao meio ambiente. Um dos resultados desta comissão foi a publicação, em 1987, do relatório Nosso Futuro Comum, que aponta a pobreza tanto como uma das principais causas como também efeito dos problemas ambientais do mundo. No relatório, a comissão estabelece o desenvolvimento sustentável como sendo aquele que atende às necessidades do presente sem comprometer a possibilidade das gerações futuras de atenderem às suas próprias necessidades. Presidida à época por Gro Brundtland, então primeira-ministra da Noruega, ficou conhecida como a Comissão de Brundtland. Nosso Futuro comum, ou Relatório de Brundtland, como é chamado até hoje, se tornou conhecido mundialmente e marcou uma revolução na discussão do desenvolvimento sustentável.

Outro evento de relevância inconteste é a Eco-92 - Conferência das Nações Unidas para o Meio Ambiente e Desenvolvimento, realizada no Rio de Janeiro, em 1992, que reuniu chefes de estado de todos os continentes, lançou o conceito de ecoeficiência e foi o ponto de partida para a criação do Protocolo de Quioto e a Agenda 21, compromissos dos líderes mundiais e das empresas de grande importância para a sustentabilidade do planeta. Nela ainda foram elaborados documentos importantes, como a Declaração do Rio e a Convenção Quadro sobre as Mudanças Climáticas.

Localmente, importantes iniciativas intensificam o debate do desenvolvimento sustentável e marcam uma mudança na mentalidade empresarial a partir da década de 90. Parte dessa nova mentalidade é refletida na expansão e profissionalização do investimento social privado pelas empresas nacionais e que se refletirá, na próxima década, no fortalecimento do movimento da Responsabilidade Social e/ou da sustentabilidade. Destaca-se nesta década, no país: a instituição da Agenda 21 brasileira; a criação do Selo Balanço Social Ibase que reconhece empresas que cumprem com critérios de transparência na divulgação da sua ação social; a criação da Lei de Crimes Ambientais; e a criação de organizações importantes e fundamentais que objetivam apoiar as empresas instaladas no Brasil nesse movimento, como a Fundação Brasileira para o Desenvolvimento Sustentável (FBDS); o Grupo de Institutos e Empresas (GIFE); o Conselho Empresarial Brasileiro de Desenvolvimento Sustentável (CEBDS); e o Instituto Ethos de Responsabilidade Social. A seguir, na figura 1, uma linha do tempo com um resumo de alguns dos acontecimentos ligados à sustentabilidade a partir da Rio 92. 


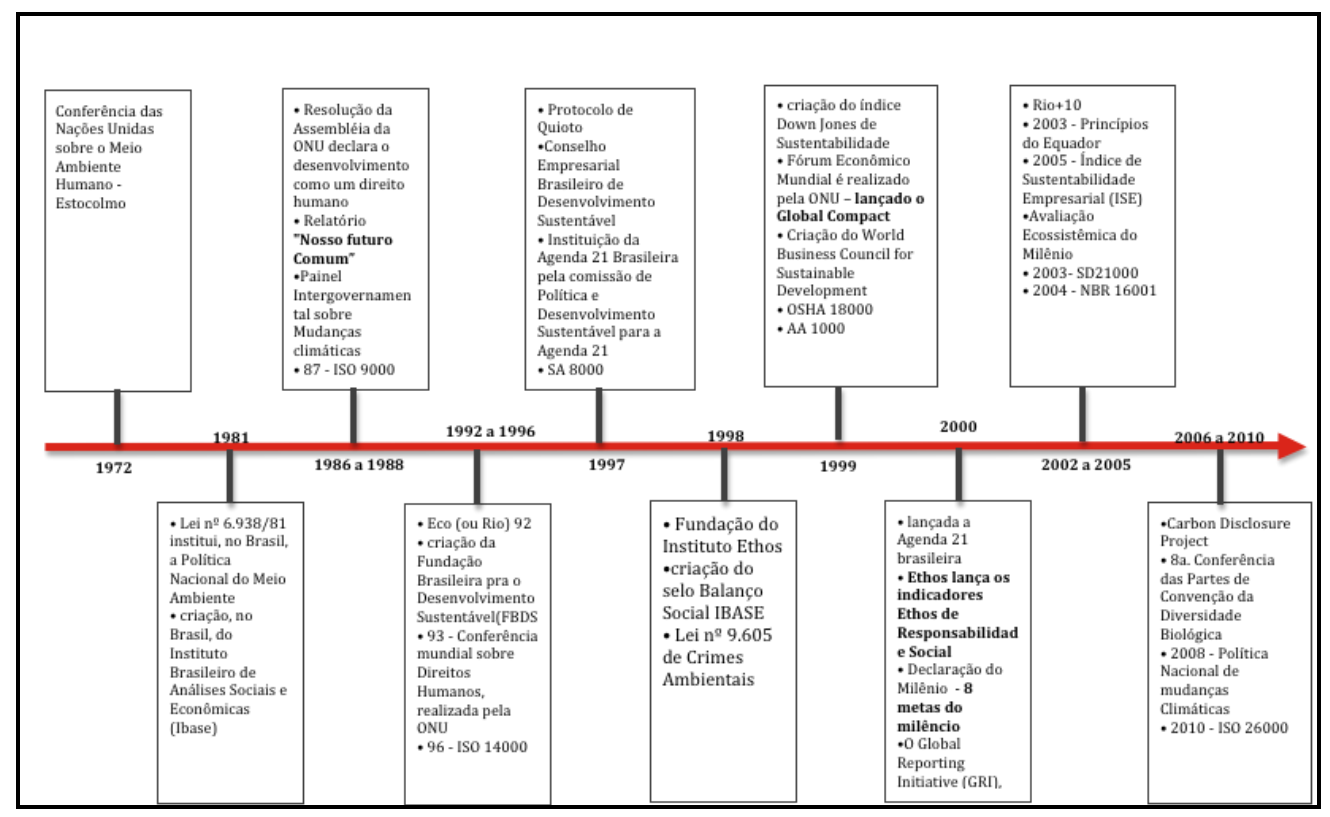

Figura 1: Evolução de algumas iniciativas acerca da sustentabilidade

Nos anos 2000, é evidente a busca do aprimoramento das questões, dos compromissos e das iniciativas das organizações de todos os setores da economia, motivados pela urgência da inserção de práticas sustentáveis. O tema sustentabilidade ganha dimensão ampla e envolve grupos multidisciplinares nos seus estudos. Uma questão central surge como premente: entender o conceito de desenvolvimento sustentável e como pode ser aplicado na prática empresarial e governamental. Nessa caminhada, notam-se grandes avanços, parte deles provenientes de instituições brasileiras de ensino reconhecidas na área de gestão, como Fundação Getúlio Vargas (FGV), Fundação Dom Cabral (FDC), Universidade de São Paulo (USP), Universidade Federal da Bahia (UFBA) e Pontifícia Universidade Católica de São Paulo (PUC-SP), para citar apenas algumas, que desenvolveram núcleos de pesquisas específicos para a sustentabilidade e vêm emprestando seus conhecimentos às empresas, à sociedade e aos governos, e hoje são seus parceiros de busca.

Essa urgência, explicitada no parágrafo acima, justifica a presente tentativa da pesquisa que originou este artigo de mapear o esforço da produção intelectual sobre o tema, o qual, entretanto, se limitou à área da administração de empresas e a apontar os avanços que a academia tem feito para auxiliar as organizações no citado processo que representa bem mais que apenas uma questão de princípio de gestão. Representa um conjunto de novos valores e práticas que devem ser incorporados à estratégia da organização para definição de posturas, norteamento das relações desta com seus meios e orientação das suas opções de negócios.

Como parte da argumentação desse estudo, optou-se por utilizar a definição de desenvolvimento sustentável do Relatório de Brundlant - desenvolvimento sustentável é aquele que atende às necessidades do presente sem comprometer a possibilidade das gerações futuras de atenderem às suas próprias necessidades. Essa definição ganhou alguns críticos severos que, em sua quase totalidade, a consideram difícil de ser implantada. Dentre os ambientalistas, divididos em preservacionistas e conservacionistas, alguns simplesmente descartam a hipótese de desenvolvimento sustentável pelo fato de acharem inconciliável desenvolvimento com preservação da natureza. A aderência voluntária e imediata de um grande número de empresas ao movimento do desenvolvimento sustentável também gerou críticas da sociedade e do mundo acadêmico que chegam a considerar a hipótese de esta ser mais uma armadilha do capitalismo. Outros críticos ainda alertam que o movimento só faz sentido se for globalizado e, por isso, será difícil implementá-lo, porque é difícil encontrar denominador comum entre países com interesses e autoridades diferentes. Exemplo é o Protocolo de Quioto sobre as emissões de gases de efeito estufa que nunca obteve consenso. Questões de caráter mundial, como aquecimento global, poluição dos 
rios e oceanos, extinção das espécies, e sérios problemas sociais, como a pobreza e a falta de infraestrutura urbana, só podem ser resolvidos com a participação de todas as nações, governos, a sociedade civil e as empresas, que cumprem papel central nesse processo, visto que muitos desses problemas socioambientais decorrem da ação direta dessas ou são motivadas por elas.

Muitas dessas críticas encontram-se no próprio Relatório de Brundlant. Com efeito, na tentativa de encontrar a forma de aplicabilidade do conceito, estratégias de correção começam a ser pensadas, como a desagregação dos elementos constitutivos do desenvolvimento sustentável em dimensões. Dentre estas, uma ganha força especial no meio empresarial e é norteadora dessa pesquisa, o modelo do Triple Bottom Line (tríplice linha de resultados líquidos: econômico, social e ambiental), desenvolvido pelo economista inglês John Elkington, da consultoria britânica SustainAbility, e que se tornou mundialmente popular.

O Triple Bottom Line propõe o dimensionamento da sustentabilidade nas dimensões econômica social e ambiental, e angariou a simpatia e aderência do empresariado por estar bem próximo da sua linguagem de resultados líquidos. O conceito não é o mais original, pois faz parte dos esquemas de desagregação anteriores, como de Ignacy Sachs, por exemplo, mas inova na forma de conceber essas três dimensões no âmbito das empresas e por utilizar uma linguagem familiar ao ambiente empresarial. Este modelo agrega também pelo fato de, como foi aceito mundialmente, é um modelo passível de ser parametrizado, além de vir inspirando outros, podendo ser aplicado em qualquer organização não empresarial.

Os argumentos contrários ao Triple Bottom Line se apresentam muito mais como ponderações do que crítica. A mais evidente é a preocupação quanto à dificuldade de se tratar temas tão complexos simultaneamente e o fato de que alguns dos princípios desse modelo serem estranhos aos métodos e práticas de gestão convencional - como é o caso da inclusão do capital social e natural em um ambiente onde o capital econômico é o mais importante.

\section{A PRÁTICA DE BALANÇOS DA PRODUÇÃO ACADÊMICA}

Os balanços críticos e retrospectivos sobre a produção acadêmica na área de administração tornou-se uma prática comumente utilizada nas últimas duas décadas. Após a observação do avanço quantitativo da produção acadêmica a partir de 1980, estudiosos de diversas áreas do conhecimento na administração sentiram a necessidade de verificar o volume e a qualidade dessa produção, até mesmo para entender as lacunas e auxiliar na qualificação da produção que viria nos próximos anos.

Foram várias essas contribuições no sentido de nortear a produção do conhecimento em administração. Como exemplo, pode-se citar o artigo de Tonelli et al. (2003) que, além de fazer um balanço da produção em Recursos Humanos no período de 1991 a 2000, explicita aprendizados de diversos estudos da mesma natureza, realizados nas áreas da administração. Em sua maioria, esses balanços avaliaram os periódicos mais renomados e significativos da Administração no Brasil, como Revista de Administração de Empresas (RAE), Revista de Administração da Universidade de São Paulo (RAUSP), Revista de Administração Pública (RAP), Revista de Administração Contemporânea (RAC), Organizações \& Sociedade (O\&S), os Anais do Encontro Anual da Associação Nacional de Pós-Graduação e Pesquisa em Administração (EnANPAD), e teses e dissertações dos programas de pós-graduação de algumas universidades brasileiras.

Ainda como contribuição dos balanços já realizados, em Tonelli et al. (2003) observou-se uma fragilidade da produção acadêmica brasileira da administração de empresas no quesito qualidade. Já no estudo de Machado (1990), constatou-se a incipiência teórico-metodológica da área e o predomínio de uma orientação específica. Em trabalhos como os de Bertero e Keinert, 2000, a temática avaliada mostrou ter raiz, predominantemente, na literatura estrangeira, sem originalidade e sem reflexões sobre a aplicabilidade dos conceitos para a realidade brasileira. Na temática do marketing, os estudos apontam para fragilidades metodológicas da produção que são consideradas por estes como questionáveis. Outros estudos, como de Vergara e Pinto (2000), notaram a

Revista de Gestão Social e Ambiental - RGSA, São Paulo, v. 5, n. 3, p. 36-52, set./dez. 2011. 
predominância de autores e periódicos internacionais na referência bibliográfica utilizada, contra uma minoria de autores nacionais.

Em termos qualitativos, esses trabalhos, conforme demonstrado por Pacheco (2003), também apontam para uma produção acadêmica mais prescritiva do que analítica, e mais dirigida para questões práticas do que para o desenvolvimento teórico-empírico da disciplina da Administração. Considerando estes balanços e retrospectivas, fica evidente que existe um crescimento e aprimoramento desta prática. Técnicas diferentes de análises têm sido empregadas e os resultados, consequentemente, mais refinados qualitativamente. Também proporcionam um cenário da área estudada, apresentam sua evolução como campo de conhecimento e referenciam tendências e perspectivas futuras.

Frente ao exposto, e aceitando o argumento de que os balanços críticos contribuem para a compreensão de uma área de conhecimento, seja autônoma ou não, a pesquisa que originou o presente artigo buscou verificar como o tema sustentabilidade evoluiu no Brasil e qual a contribuição da produção acadêmica nesse tema para constituir conhecimento relevante em administração.

É importante ressaltar que, embora a quantidade de material produzido não seja fator determinante por si só, ao se fazer o balanço quantitativo, em certo sentido, consegue-se verificar o grau de importância que o tema tem tido nas instituições de ensino de ponta no Brasil. Associado a isso, sabe-se que as instituições de ensino mais relevantes na área de gestão possuem papel importante como parceiros da iniciativa empresarial e dos governos para o desenvolvimento do país. Os conhecimentos dessas instituições, comumente, extrapolam seus muros e passam a balizar o trabalho de lideranças que, muitas vezes, solicitam trabalhos acadêmicos para consolidação de transformações das suas práticas. Assim a quantidade de textos publicados na área por tais Instituições bem pode configurar-se em indicativo de sua relevância para o meio empresarial.

\section{MÉTODO DE PESQUISA}

Este artigo é resultado de uma pesquisa que tem como objetivo fazer uma revisão sistemática e avaliação crítica da produção científica brasileira sobre o tema sustentabilidade. Foram também utilizadas análises quantitativas para mensurar os esforços despendidos nas publicações, demonstrando como são distribuídas: por temática ou dimensão da sustentabilidade; por autor; por instituição de ensino e estado; e por tipo de metodologia adotada na pesquisa.

Como objeto de estudo, foram elencados para análise os artigos sobre o tema da sustentabilidade, entre os anos de 2000 e 2009, publicados nos Anais do EnANPAD e nos seguintes periódicos: Revista de Administração de Empresas (RAE), Revista de Administração Pública (RAP) e Organizações \& Sociedade (O\&S). A escolha do EnANPAD e destes periódicos levou em consideração as análises de impacto já citadas, como as de Machado-da-Silvaet al. (2008), Tonelliet al. (2003) Bertero, Binder e Vasconcelos (2003) e Pacheco (2003) que colocaram o EnANPAD entre os principais eventos da Administração de Empresas no Brasil, assim como os três periódicos escolhidos como os que tiveram a maior repercussão ou visibilidade na comunidade científica da área de Administração de Empresas, podendo, portanto, serem considerados dentre os de maior relevância na produção científica da administração no Brasil.

A RAE é publicada pela Escola de Administração de Empresas de São Paulo, da Fundação Getúlio Vargas (FGV-EAESP) e foi a primeira revista científica brasileira na área. A RAP, por sua vez, é publicada trimestralmente pela Escola Brasileira de Administração Pública e de Empresas da Fundação Getúlio Vargas do Rio de Janeiro (FGV-EBAPE). E a revista O\&S é uma publicação trimestral da Escola de Administração da Universidade Federal da Bahia (EAUFBA).

Ainda inspirados nos balanços da produção científica mencionados no decorrer deste artigo, foram considerados como critérios de análise para o estudo: a temática da produção científica sobre o tema sustentabilidade; a quantidade de artigos publicados por instituição de ensino e suas respectivas regiões geográficas; a quantidade de artigos publicados por autor ou conjunto de

Revista de Gestão Social e Ambiental - RGSA, São Paulo, v. 5, n. 3, p. 36-52, set./dez. 2011. 
autores; o perfil metodológico do artigo; e a representatividade do tema nas publicações da área de Administração.

Para a primeira coleta de dados, foram selecionados, através dos sites dos periódicos e do EnANPAD, os artigos que abordam a sustentabilidade, através da filtragem das palavras-chave Sustentabilidade e Desenvolvimento Sustentável contidas ou no título ou nas palavras-chave ou no resumo. A inclusão da palavra desenvolvimento sustentável deve-se ao fato de que os dois termos são amplamente utilizados na literatura e tratam da mesma área. Ainda nesta primeira coleta de dados, não houve busca por seção temática, pois se detectou a inexistência de grupo de estudos específico no EnANPAD ou editoria sobre o tema nos periódicos. É importante esclarecer que na filtragem, todos os artigos duplicados foram desconsiderados a partir da sua segunda publicação.

Logo após, em uma segunda filtragem dos artigos selecionados, estes foram divididos por abordagem temática dentro da sustentabilidade, classificando-os por dimensões, segundo o critério do Triple BottonLine: dimensão social, dimensão ambiental ou dimensão econômica ou a congruência de duas ou três dessas dimensões.

A análise do perfil metodológico dos artigos - tanto dos periódicos como os do Enapad classificaram-os em teóricos, empírico ou teoríco-empírico. Os artigos empíricos e teóricoempíricos foram subclassificados em qualitativo, quantitativo ou quali-quanti. Os teóricos foram classificados como ensaio de revisão, proposição ou sistematização. No caso dos estudos qualitativos de estudos de caso, ainda houve a classificação dos mesmos em estudo de caso único e estudo de caso múltiplo para os estudos de três ou mais casos.

A pesquisa apresentou algumas limitações na análise da instituição à qual o autor pertencia à época da publicação, pois, nos artigos do EnANPAD, este dado não consta e, nem sempre foi possível localizar o mesmo na plataforma Lattes.

\section{A PRODUÇÃO ACADÊMICA NACIONAL SOBRE SUSTENTABILIDADE}

Nota-se que o tema sustentabilidade ainda encontra-se em fase de evolução nas publicações pesquisadas e no EnANPAD. Foram analisados 106 artigos, em dez anos de publicação ou evento, sendo 27 nos periódicos e 79 no EnANPAD. Há diferença na variação quantitativa da série histórica em relação aos periódicos e ao EnANPAD (Tabela 1). No EnANPAD, o tema apresenta um aumento gradual ao longo do período, especialmente a partir de 2005, quando os debates na sociedade também ganham maior ênfase.

Tabela 1: Artigos por Periódico e EnANPAD

\begin{tabular}{|c|c|c|c|c|c|c|}
\hline Ano & RAE & RAP & O\&S & $\begin{array}{c}\text { Total de } \\
\text { periódicos }\end{array}$ & EnANPAD & Total \\
\hline $\mathbf{2 0 0 0}$ & 3 & 3 & 0 & 6 & 1 & 7 \\
\hline $\mathbf{2 0 0 1}$ & 2 & 0 & 2 & 4 & 2 & 6 \\
\hline $\mathbf{2 0 0 2}$ & 0 & 0 & 0 & 0 & 2 & 2 \\
\hline $\mathbf{2 0 0 3}$ & 0 & 2 & 0 & 2 & 3 & 5 \\
\hline $\mathbf{2 0 0 4}$ & 0 & 3 & 1 & 4 & 4 & 8 \\
\hline $\mathbf{2 0 0 5}$ & 0 & 1 & 0 & 1 & 8 & 9 \\
\hline $\mathbf{2 0 0 6}$ & 0 & 4 & 0 & 4 & 10 & 14 \\
\hline $\mathbf{2 0 0 7}$ & 0 & 2 & 0 & 2 & 15 & 17 \\
\hline $\mathbf{2 0 0 8}$ & 1 & 1 & 1 & 3 & 18 & 21 \\
\hline $\mathbf{2 0 0 9}$ & 0 & 1 & 0 & 1 & 16 & 17 \\
\hline Total & $\mathbf{6}$ & $\mathbf{1 7}$ & $\mathbf{4}$ & $\mathbf{2 7}$ & $\mathbf{7 9}$ & $\mathbf{1 0 6}$ \\
\hline
\end{tabular}

Fonte: Dados da pesquisa.

O contrário acontece nos periódicos, nos quais o volume de artigos do tema decresce. Entre 2001 e 2004, nos periódicos, foram publicados 16 artigos, sendo que 10 destes foram publicados 
nos dois primeiros anos, 2000 e 2001. A partir desses dois primeiros anos, o número de artigos cai. $\mathrm{Na}$ RAE e O\&S, entre 2002 e 2009, somente foram publicados sobre o tema um e dois artigos, respectivamente. Entre os periódicos, a RAP, a partir de 2003, foi o único que manteve o tema sempre presente em todos os anos. Outro dado curioso é o fato de que, em 2009, 16 artigos nos Anais do EnANPAD abordaram o tema sustentabilidade contra apenas 1 nos periódicos. Na figura 2 é possível visualizar de forma mais contundente a contradição na evolução dos artigos nos periódicos e no EnANPAD.

Figura 2: Evolução das publicações por Periódico e EnANPAD

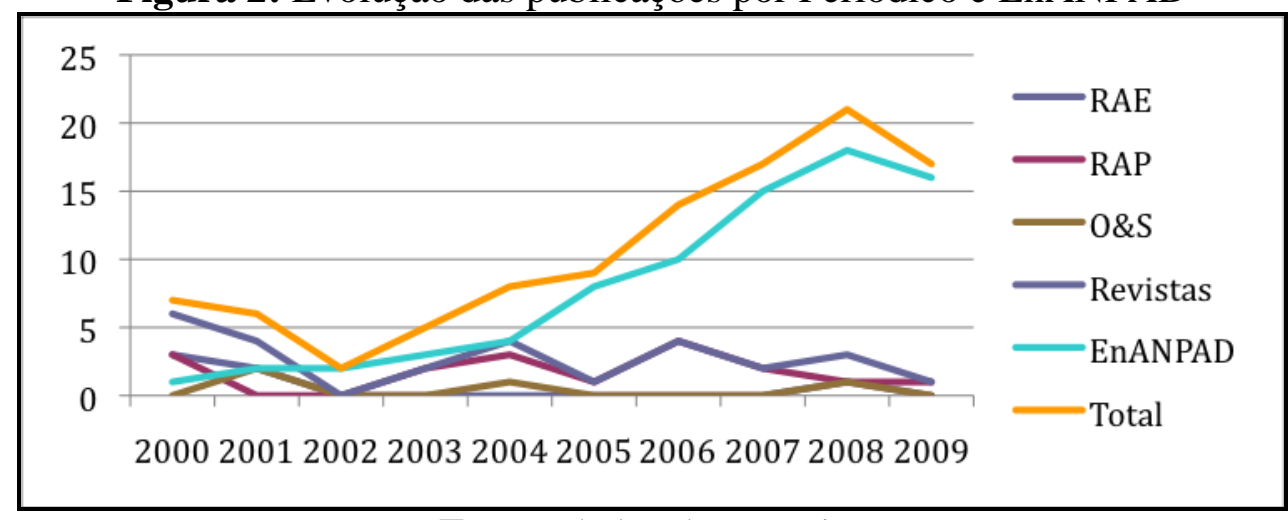

Fonte: dados da pesquisa

Em contra ponto ao pouco interesse das publicações nacionais de administração sobre a sustentabilidade, e mesmo o pequeno número de artigos no EnANPAD - principalmente se comparado com temas abordados em outros balanços retrospectivos realizados e já citados neste artigo -, o progresso da temática sustentabilidade no mercado editorial nacional e internacional mostra avanços, assim como as universidades começam a despertar para a sustentabilidade, incluindo o tema não ainda como área de pesquisa autônoma, mas em linhas de pesquisa das áreas de relações internacionais, economia, administração e engenharia de meio ambiente, dentre outras.

\subsection{A análise da Temática}

As áreas temáticas dos artigos, dentro da sustentabilidade, foram analisadas sobre a perspectiva do Triplle Bottom line, conforme justificado na metodologia, distribuindo entre as dimensões ambiental, social e econômica. Ainda nesta perspectiva, consideraram-se os artigos que tratam de um ou mais temas concomitantes, tendo sido classificados como: i) artigos que tratam conjuntamente das três dimensões econômica, social e ambiental (E/S/A); ii) os que tratam das dimensões econômica e social (E/S); iii) os que abordam as dimensões econômica e ambiental (E/A); e iv) os que abordam o social e ambiental (S/A). Segundo Elkington, autor dessa proposta de dimensionamento da sustentabilidade em uma linha tríplice de resultados, as organizações devem considerar esses três pilares conjuntamente em sua estratégia de sustentabilidade.

Os dados analisados mostram que a tendência foi de estudos contemplando as três dimensões da sustentabilidade conjuntamente (31\%), seguido pela abordagem apenas da dimensão econômica (23\%), a social (19\%) e a ambiental (11\%). As dimensões tratadas por agrupamento em par (econômica e social; econômica e ambiental; e social e ambiental) não tiveram representatividade significativa na análise (Tabela 2).

Tabela 2: Classificação da temática

\begin{tabular}{|c|c|c|c|c|c|c|c|}
\hline Ano & Ambiental & Social & Econômica & E/S/A & E/S & E/A & S/A \\
\hline $\mathbf{2 0 0 0}$ & 3 & 0 & 0 & 2 & 0 & 1 & 1 \\
\hline $\mathbf{2 0 0 1}$ & 0 & 3 & 1 & 2 & 0 & 0 & 0 \\
\hline $\mathbf{2 0 0 2}$ & 0 & 0 & 2 & 0 & 0 & 0 & 0 \\
\hline
\end{tabular}

Revista de Gestão Social e Ambiental - RGSA, São Paulo, v. 5, n. 3, p. 36-52, set./dez. 2011. 


\begin{tabular}{|l|l|l|l|l|l|l|l|}
\hline $\mathbf{2 0 0 3}$ & 0 & 1 & 1 & 2 & 0 & 0 & 1 \\
\hline $\mathbf{2 0 0 4}$ & 1 & 1 & 2 & 4 & 0 & 0 & 0 \\
\hline $\mathbf{2 0 0 5}$ & 0 & 4 & 2 & 1 & 1 & 0 & 1 \\
\hline $\mathbf{2 0 0 6}$ & 3 & 7 & 2 & 1 & 0 & 0 & 1 \\
\hline $\mathbf{2 0 0 7}$ & 2 & 2 & 6 & 6 & 0 & 0 & 1 \\
\hline $\mathbf{2 0 0 8}$ & 1 & 3 & 2 & 12 & 1 & 2 & 0 \\
\hline $\mathbf{2 0 0 9}$ & 2 & 0 & 7 & 2 & 3 & 3 & 0 \\
\hline Total & $\mathbf{1 2}$ & $\mathbf{2 1}$ & $\mathbf{2 5}$ & $\mathbf{3 2}$ & $\mathbf{5}$ & $\mathbf{6}$ & $\mathbf{5}$ \\
\hline
\end{tabular}

Fonte: Dados da pesquisa.

Quando analisada a presença das temáticas social, ambiental e econômica nos artigos, durante todo o período estudado, independente de tratarem de duas ou três das dimensões conjuntamente, nota-se que há uma distribuição uniforme entre elas (figura 3).

Figura 3: Temática por todo período analisado

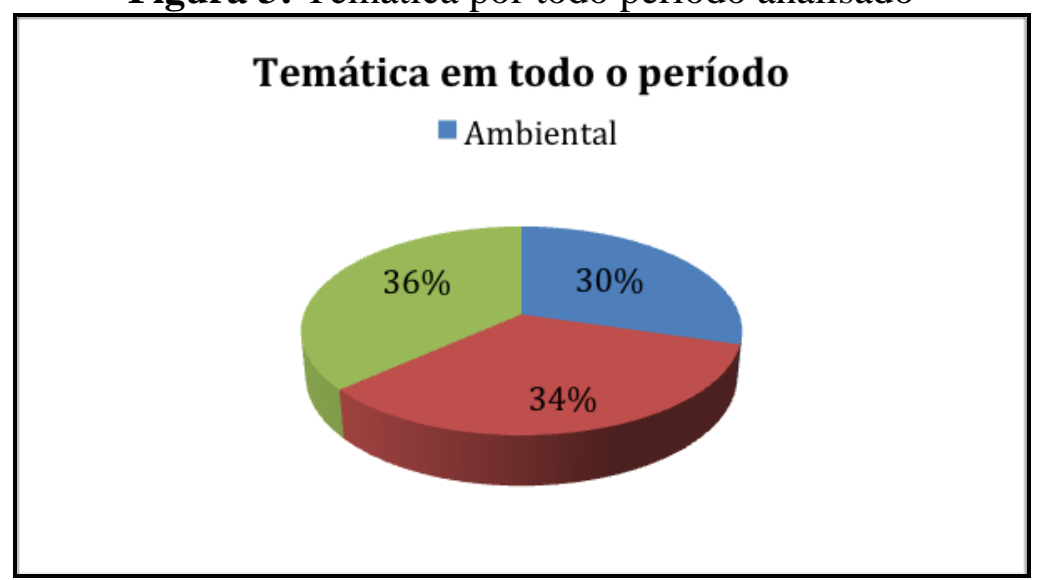

Fonte: Dados da pesquisa.

Conforme pode-se observar na Figuras 4 e Tabela 3, ao longo do período estudado, a evolução gradual do interesse pelas dimensões econômica, social e ambiental se dá de forma semelhante somente após o ano de 2007. Até este ano, cada uma delas segue uma trajetória diferente. No primeiro ano da série, o tema ambiental domina com 53\% dos artigos; no segundo 2001 - o social predomina; e no terceiro, só há artigos tratando da dimensão econômica. Nos anos seguintes - de 2004 a 2006 o tema social tem posição de destaque frente aos outros dois. E, a partir de 2007, há uma homogeneidade na divisão dos artigos entre os três temas.

A princípio, pode-se pressupor que o interesse pela dimensão ambiental e social no início seja reflexo do grande número de iniciativas e movimentos locais e internacionais realizados em prol do desenvolvimento sustentável que surgiram da metade dos anos noventa para frente e neste artigo apresentadas na Figura 1 Evoluções das iniciativas acerca da Sustentabilidade. 
Figura 4: Temática distribuída no período estudado

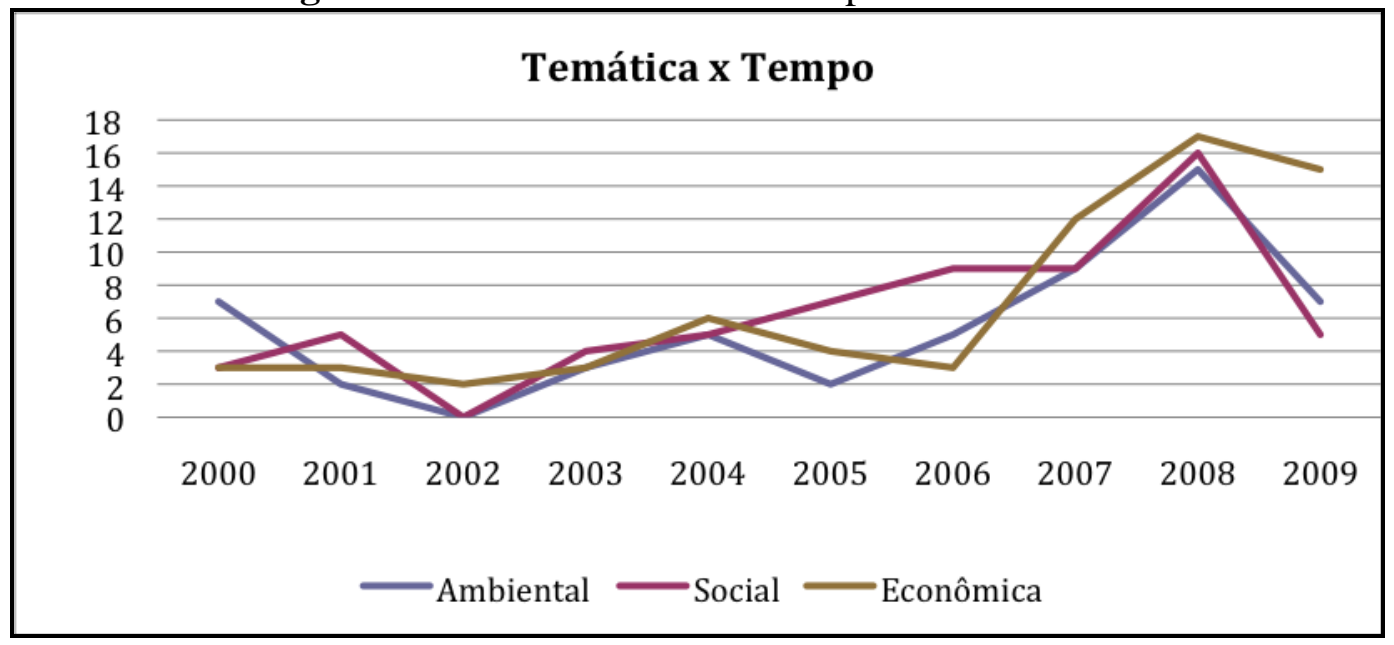

Fonte: Dados da pesquisa.

Tabela 3: Temática distribuída no período estudado

\begin{tabular}{|c|c|c|c|}
\hline Ano & Ambiental & Social & Econômica \\
\hline $\mathbf{2 0 0 0}$ & 7 & 3 & 3 \\
\hline $\mathbf{2 0 0 1}$ & 2 & 5 & 3 \\
\hline $\mathbf{2 0 0 2}$ & 0 & 0 & 2 \\
\hline $\mathbf{2 0 0 3}$ & 3 & 4 & 3 \\
\hline $\mathbf{2 0 0 4}$ & 5 & 5 & 6 \\
\hline $\mathbf{2 0 0 5}$ & 2 & 7 & 4 \\
\hline $\mathbf{2 0 0 6}$ & 5 & 9 & 3 \\
\hline $\mathbf{2 0 0 7}$ & 9 & 9 & 12 \\
\hline $\mathbf{2 0 0 8}$ & 15 & 16 & 17 \\
\hline $\mathbf{2 0 0 9}$ & 7 & 5 & 15 \\
\hline Total & $\mathbf{5 5}$ & $\mathbf{6 3}$ & $\mathbf{6 8}$ \\
\hline
\end{tabular}

Fonte: Dados da pesquisa.

Afora o estudo das dimensões, mas ainda quanto à temática, nota-se grande interesse, dentre os estudos quantitativos, por criação de modelo de medida de desempenho da sustentabilidade das empresas ou de projetos específicos, especialmente nos artigos dos Anais do EnANPAD. Já nos periódicos - englobando todos os artigos independente da sua natureza metodológica -, há uma predominância de artigos mais generalizantes sobre as temáticas e, em sua maioria, são reflexões sobre a realidade e sobre os conceitos de sustentabilidade, ou mesmo reflexões e críticas aos processos e mecanismos defendidos como de apoio à sustentabilidade das empresas ou da gestão pública, tais como normatização, métodos de planejamento participativo, modelos de gestão, indicadores etc. Há também, especialmente nos estudos publicados nos periódicos, uma grande maioria de estudos que visam contribuir para as discussões atuais, indicando possíveis caminhos de investigação empírica e contextualizando a temática ao longo da história ou confrontando-a com as teorias da administração.

\subsection{Metodologia da produção científica sobre sustentabilidade}

Quanto à opção metodológica, os artigos foram classificados em teóricos, teórico-empíricos e empíricos. Os empíricos e teórico-empíricos foram classificados em estudos qualitativos (quali), quantitativos (quanti) e qualitativos/quantitativos (quali/quanti). No somatório total de periódicos e EnANPAD, observa-se a predominância dos artigos teórico-empíricos, o que não se repete quando observa-se isoladamente o grupo de periódicos e o grupo do EnANPAD. No total dos periódicos, 
$67 \%$ dos estudos são de cunho teórico, e no EnANPAD, apenas 15\% são da mesma natureza. Ao contrário, no EnANPAD, 85\% dos estudos são de cunho empíricos ou teórico-empíricos, contra $33 \%$ nos periódicos (figuras 5 e 6).

Figura 5: Método de Pesquisa

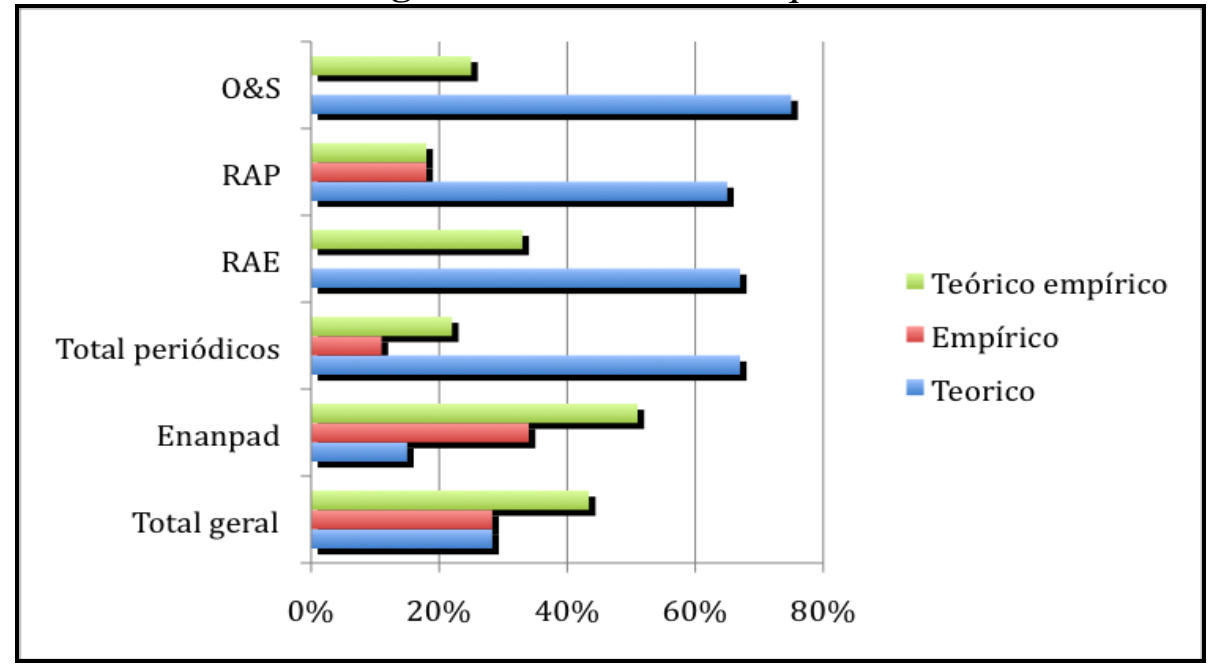

Fonte: Dados da pesquisa.

Figura 6: Método de Pesquisa por tipo de publicação.

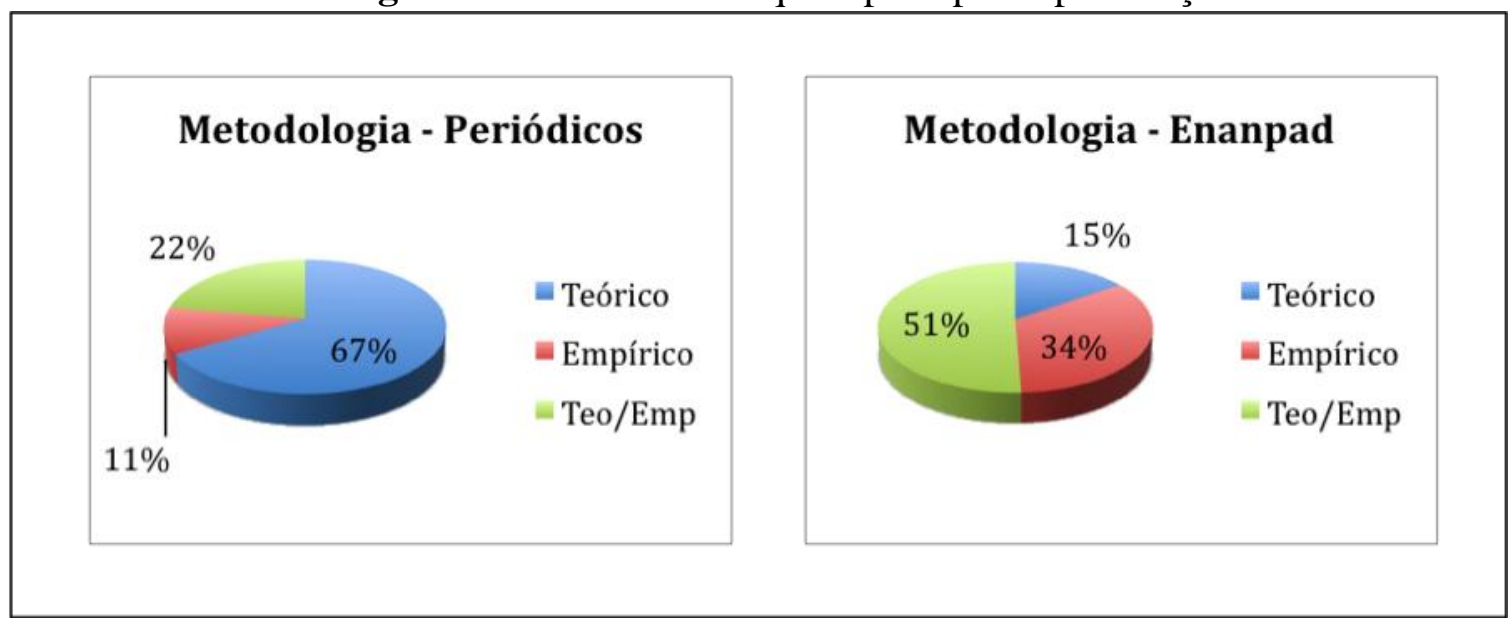

Fonte: Dados da pesquisa.

Quanto aos estudos empíricos e teórico-empíricos, os dados mostram uma predominância de trabalhos qualitativos, tanto na análise do total de artigos, quanto na análise separadamente do total de artigos do EnANPAD e dos periódicos (figuras 7 e 8). 
Figura 7: Estudos Empíricos.

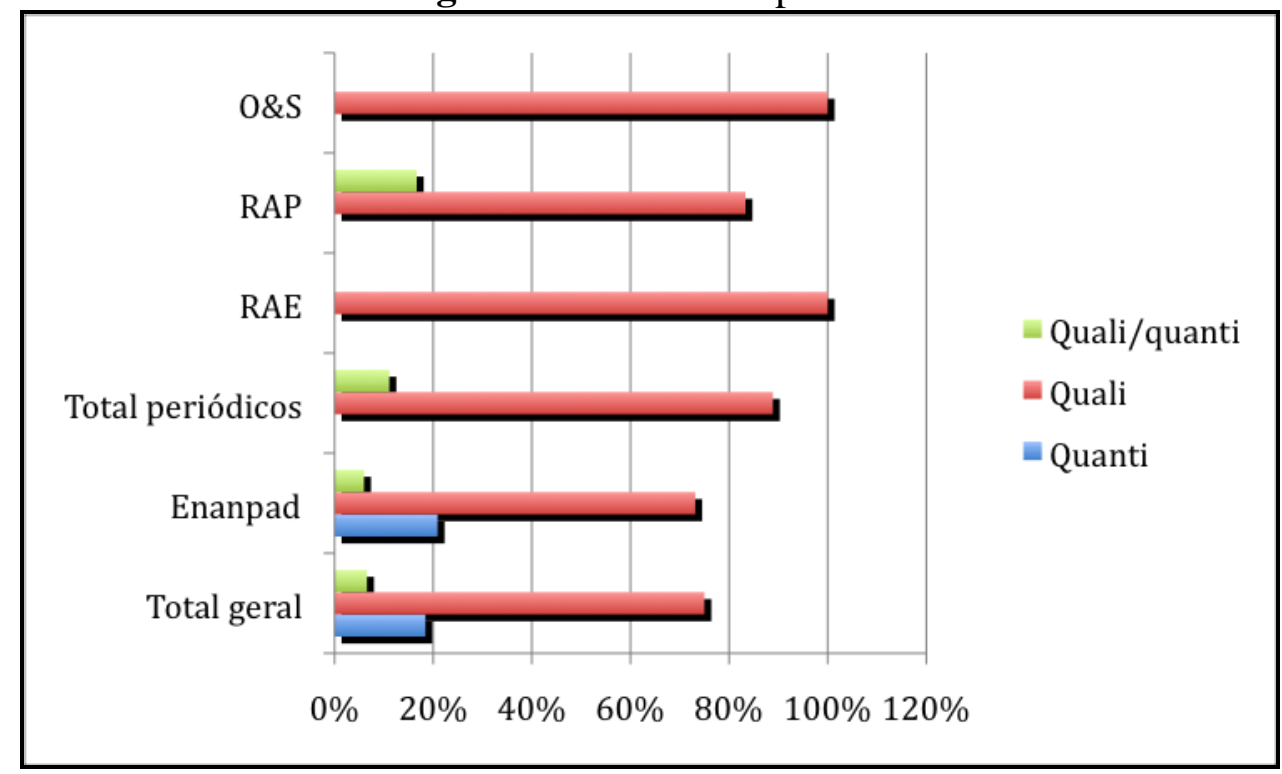

Fonte: Dados da pesquisa.

Figura 8: Estudos empíricos por tipo de publicação

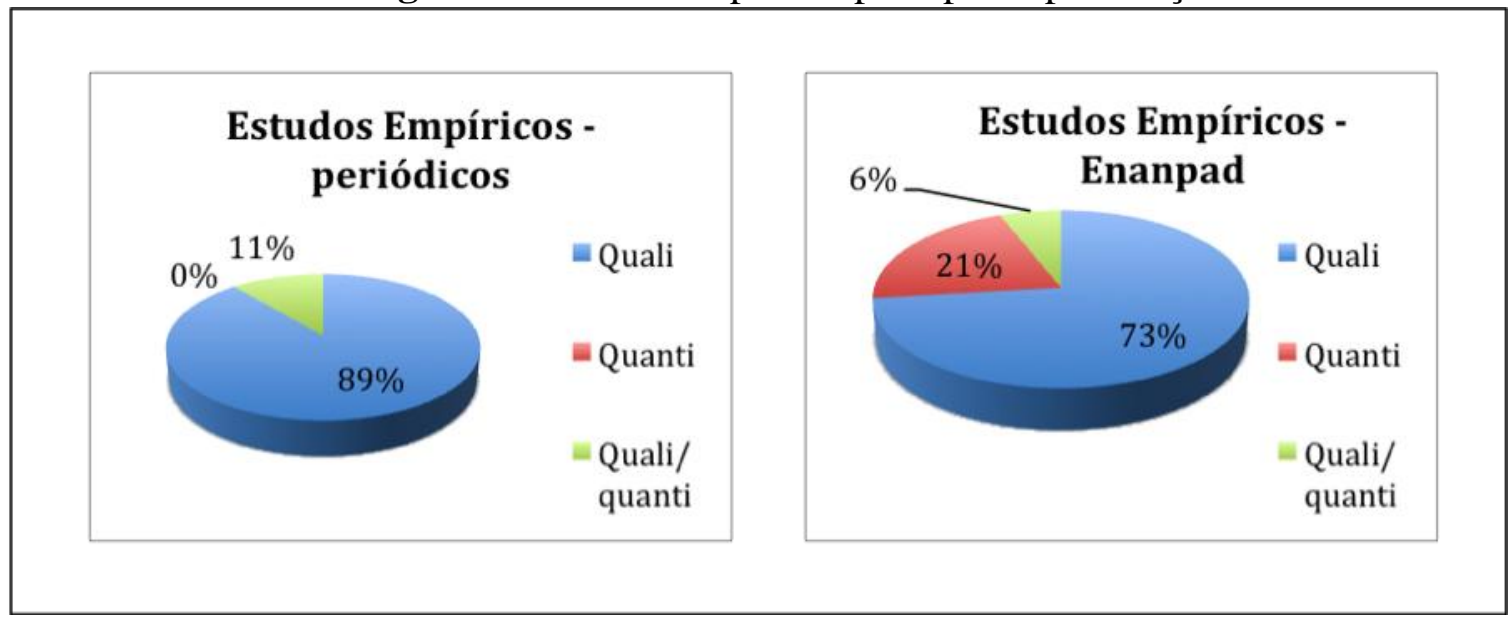

Fonte: Dados da pesquisa.

Nos estudos de caso, ao computar-se o total dos artigos, observa-se que há maioria de estudos de caso únicos (59\%) sobre os múltiplos (41\%), mas não pode-se chamar de predominância. Porém, tratando apenas o total de periódicos, é interessante notar que há uma predominância por estudos de caso único (89\%) que configuram-se mais como exemplos (figura 9). Tal fato caracteriza o mal uso da estratégia da metodologia de estudo de caso que considera como válida cientificamente somente a pesquisa que envolve múltiplos casos. Outros balanços retrospectivos citados neste artigo, como os de Tonelliet al. (2003) e Bertero, Binder e Vasconcelos (2003), chegaram a esta mesma conclusão. 
Figura 9: Estudos de Caso

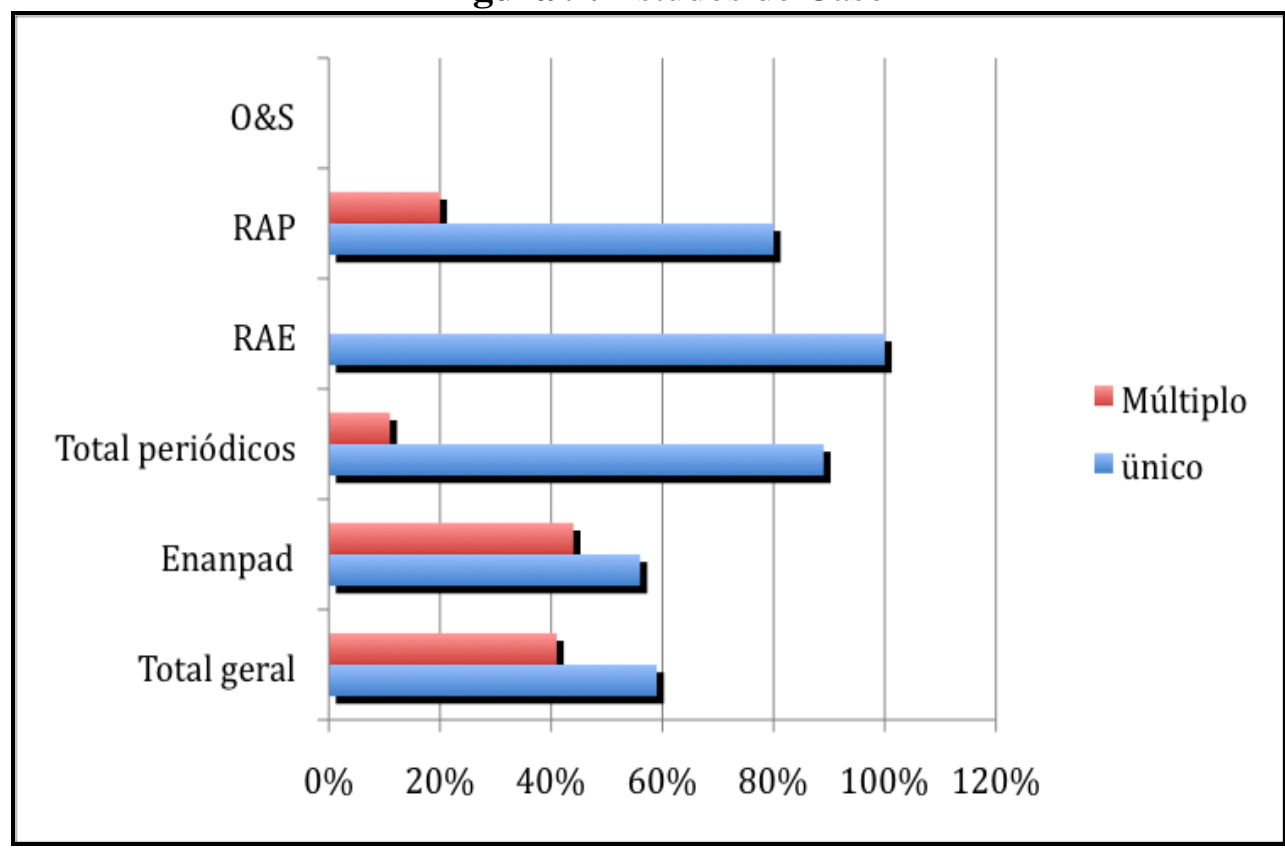

Fonte: Dados da pesquisa.

As pesquisas de cunho teórico, predominantes nos periódicos, foram subclassificadas em ensaio: de revisão, sistematização e proposições de modelos ou teorias, sendo que tanto no EnANPAD como nos periódicos, metade dos estudos teóricos analisados são de revisão crítica ou bibliográfica (figura 10).

Figura 10: Estudos teóricos por tipo de publicação

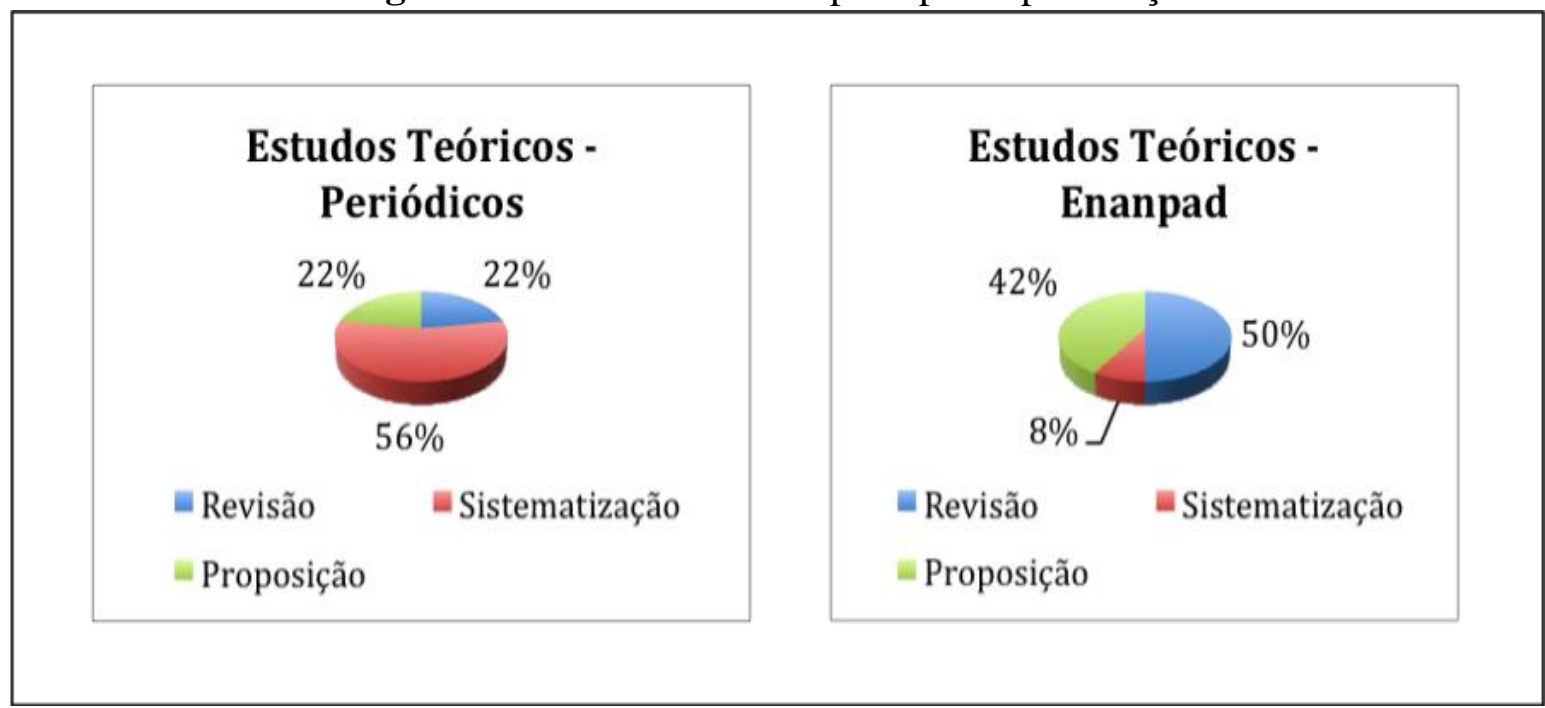

Fonte: Dados da pesquisa.

\subsection{Quem produz e onde se concentra a produção}

Os dados mostram que não há uma participação por autor em mais que 4 artigos do total analisado. Apenas um autor possui essa característica, outros dois participam de 3 artigos cada e outros 16 participam em dois artigos cada. O restante dos autores só estão presentes em um único artigo (tabela 4). 
Tabela 4: Autores mais Profícuos

\begin{tabular}{|l|c|c|c|c|c|c|}
\hline \multicolumn{1}{|c|}{ Autor } & $\begin{array}{c}\text { Total de } \\
\text { artigos }\end{array}$ & \% & RAE & RAP & O\&S & EnANPAD \\
\hline José Carlos Barbieri & 4 & $3,77 \%$ & & 2 & & 2 \\
\hline Carlos Alberto Cioce Sampaio & 3 & $2,83 \%$ & & 1 & & 2 \\
\hline Carlos Ricardo Rossetto & 3 & $2,83 \%$ & & 1 & & 2 \\
\hline Hans Michael van Bellen & 3 & $2,83 \%$ & & & & 3 \\
\hline Adriana Marques Rossetto & 2 & $1,89 \%$ & & 1 & & 1 \\
\hline Alain Charles Martinet & 2 & $1,89 \%$ & & & & 2 \\
\hline Allene Carvalho Lage & 2 & $1,89 \%$ & & & & 2 \\
\hline Elaine Ferreira & 2 & $1,89 \%$ & & & & 2 \\
\hline Eliza Coral & 2 & $1,89 \%$ & & & & 2 \\
\hline Eugenio Avila Pedrozo & 2 & $1,89 \%$ & & & & 2 \\
\hline José Célio Silveira Andrade & 2 & $1,89 \%$ & & 1 & 1 & \\
\hline Julyana Goldner Nunes & 2 & $1,89 \%$ & & & & 2 \\
\hline Lúcia Rejane da R. G. Madruga & 2 & $1,89 \%$ & & & & 2 \\
\hline Luciano Barin Cruz & 2 & $1,89 \%$ & & & & 2 \\
\hline Marcos Cohen & 2 & $1,89 \%$ & & & & 2 \\
\hline Maria Tereza Saraiva de Souza & 2 & $1,89 \%$ & & & & 2 \\
\hline Paulo Maurício Selig & 2 & $1,89 \%$ & & & & 2 \\
\hline Priscila Borin de Oliveira Claro & 2 & $1,89 \%$ & & & & 2 \\
\hline Teresia Diana de M. Soares & 2 & $1,89 \%$ & & 2 & 1 & \\
\hline Valcemiro Nossa & 2 & $1,89 \%$ & & & & 2 \\
\hline Outros & 1 & $0,94 \%$ & & & & \\
\hline
\end{tabular}

Fonte: Dados da pesquisa.

Os autores e suas respectivas universidades que concentram a produção acadêmica encontram-se nos estados de São Paulo, Rio de Janeiro, Santa Catarina, Rio Grande do Sul e Bahia (Tabela 5 e Figura 11). A grande maioria das instituições e autores mais profícuos (74\%) se concentra nos estados do sudeste e sul do Brasil. Nos estados de São Paulo e Rio de Janeiro estão $27 \%$ e $22 \%$, respectivamente, desse grupo, $20 \%$ em Santa Catarina e $15 \%$ no Rio Grande do Sul. A Bahia o quinto estado que concentra a produção nessa temática (13\%), único estado com representanção significativa fora do eixo sudeste -sul.

Tabela 5: Autores por IES

\begin{tabular}{|c|c|c|}
\hline IES & Autores & \% \\
\hline USP & 18 & $7,50 \%$ \\
\hline UFBA & 14 & $5,83 \%$ \\
\hline FGV(SP) & 13 & $5,42 \%$ \\
\hline PUC(RJ) & 13 & $5,42 \%$ \\
\hline UFRGS & 13 & $5,42 \%$ \\
\hline UFSC & 11 & $4,58 \%$ \\
\hline Univali & 10 & $4,17 \%$ \\
\hline FUCAPE & 9 & $3,75 \%$ \\
\hline UFLA & 7 & $2,92 \%$ \\
\hline UFRJ & 7 & $2,92 \%$ \\
\hline Unicamp & 6 & $2,50 \%$ \\
\hline
\end{tabular}

Fonte: Dados da pesquisa.

Revista de Gestão Social e Ambiental - RGSA, São Paulo, v. 5, n. 3, p. 36-52, set./dez. 2011. 
Figura 11: IES por Estado

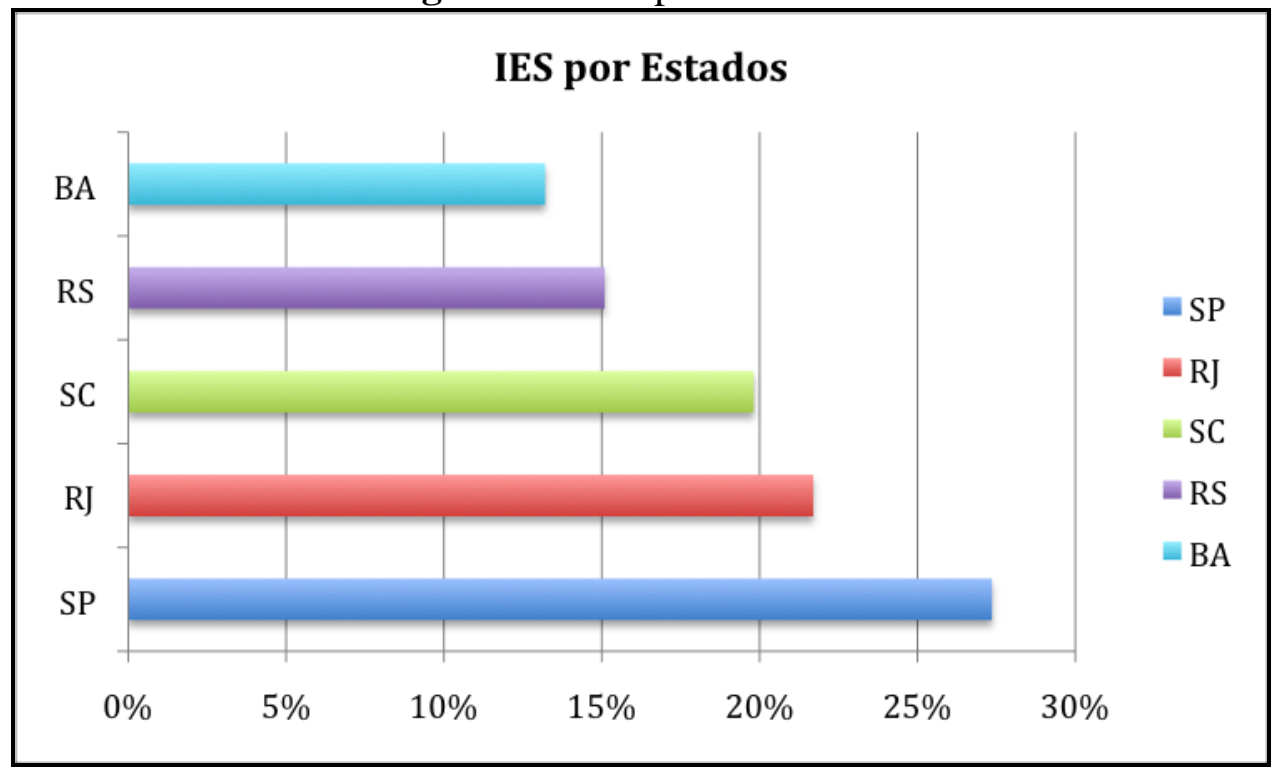

Fonte: Dados da pesquisa.

\section{CONSIDERAÇÕES FINAIS}

Não restam dúvidas que o comportamento da produção científica analisada confirma as premissas do presente estudo, demonstrando que a sustentabilidade ainda desperta interesse comedido dos autores nacionais.

Nota-se, entretanto, que a curva de volume de publicações, especialmente dos periódicos, segue a tendência da linha do tempo da evolução do tema apenas no início do período analisado, caindo drasticamente no final do mesmo, em contra-ponto ao EnANPAD. Muito provavelmente a concentração da produção dos periódicos no início dos anos 2000 pode ser explicada pela ampliação do debate no fim dos anos 1990 e pela criação de institutos de promoção da sustentabilidade (como Instituto Ethos de Responsabilidade Social e Conselho Empresarial Brasileiro para o Desenvolvimento Sustentável), além, da difusão dos termos de importantes acordos mundiais, como o Pacto Global. Porém, a queda não apresenta explicação óbvia e somente poderá ser esclarecida com pesquisa mais ampla envolvendo avaliadores de artigos de todos os periódicos pesquisados publicações.

Por seu turno, ao longo dos anos 2000, após a consolidação dos debates da década anterior, nitidamente as publicações se deslocam de questões teóricas e analíticas para aquelas com caráter descritivo. Desse modo, não é de surpreender que, no período, a maior produção sobre o tema esteja vinculada aos anais do ENANPAD, sendo também que podemos considerar normal que a imensa maioria de tais texto refiram-se somente a revisões.

$\mathrm{Na}$ mesma direção, vale salientar o significativo e gradual crescimento de textos a partir de 2007, anos que antecedem a Conferência do Clima em Copenhague, com destaque para a temática econômica que, ao menos em termos do volume de produção, ganha relevância se comparada com a social e, principalmente, a ambiental.

Observe-se, entretanto, que nos últimos anos, dentre os objetos de estudos, verifica-se grande interesse na busca por modelos de medida de desempenho da sustentabilidade das empresas ou de projetos específicos, entretanto, identifica-se simultaneamente a predominância de trabalhos estritamente qualitativos, o que em certo sentido contraria o aparente intuito de realizar mensurações de desempenhos. Tal fato, certamente, indica que nesses textos os modelos de medida são apresentados a partir de modelos pré-existentes o que, em algum sentido, induz a interpretação de ser baixa a inovação temática apresentada nos trabalhos.

A despeito da tendência acima, não restam dúvidas de que trabalhos de cunho teórico 
continuam sendo publicados, contudo, fundamentalmente em periódicos, sendo pouco observados nos anais do ENANPAD, que, por seu turno, é o principal canal de difusão do tema, especialmente por se tratar de um espaço de divulgação da produção acadêmica mais acessível, e com maior capacidade de absorção pelo limite maior, para apresentação de trabalhos oriundos de pesquisas de dissertações e teses.

Os dados apontam também para o fato de que várias Instituições empreendem grande esforço em tratar o tema nas suas mais diversas dimensões, sendo evidente, e o volume de produção o confirma, que algumas delas, exatamente as de maior tradição, em certo sentido, encontram-se na ponta dos debates.

Entretanto, tal hegemonia não se replica na publicação de artigos em revistas, espaços que autores oriundos de Instituições de maior e menor tradição dividem igualmente. Tal constatação traduz as hipóteses de que a ANPAD privilegia estudos empíricos em detrimento aos teóricos ou que os pesquisadores de centros menos tradicionais têm pouca proximidade com a Associação. Seja como for, tais hipóteses não foram testadas por não ser o objetivo do presente trabalho.

De toda forma, a pesquisa realizada confirma as premissas que a motivou, indicando que no meio acadêmico ainda há muito que debater sobre o tema sustentabilidade que, inequivocamente, possui grande relevância, quer por motivos científicos, quer em termos práticos para a Administração.

A pesquisa que originou este artigo teve caráter mais genérico e, portanto, não consegue delinear o caminho das discussões científicas acerca da sustentabilidade. Os artigos estudados tratam de temas diversos e igualmente distribuídos entre as temáticas econômica, ambiental e social, não oferecendo pistas para uma concentração de interesse da área no atual momento. Porém, pela inexistência de estudos retrospectivos ou meta-estudos nos periódicos e anais do EnANPAD analisados sobre a sustentabilidade, pretende-se, com este artigo, contribuir também para a motivação do interesse da comunidade científica para esta demanda.

\section{REFERÊNCIAS}

ADRIAN, H; RICHARDSON, Julie.The Triple Bottom Line: does it all add up? London, Earthscan, 2005.

BARBIERI, José Carlos E CAJAZEIRA, Jorge E.R, Responsabilidade Social Empresarial e empresa sustentável: da teoria à pratica. São Paulo: Saraiva, 2009.

BERTERO, C. O. e KEINERT, T. M. M, A evolução da análise organizacional no Brasil (1961 93). Revista de Administração de Empresas, São Paulo, v.34, n.3, maio/junho, 1994, p 81-90.

COMISSÃO MUNDIAL SOBRE O MEIO AMBIENTE E DESENVOLVIMENTO. Nosso Futuro Comum. Rio de Janeiro: Editora FGV, 1991.

ELKINGTON, John. Canibais com garfo e faca: Makron Books, 2001.

FORRESTER, J. W. Limites do Crescimento. São Paulo: Perspectiva, 1972.

GUIA DE COMUNICAÇÃO E SUSTENTABILIDADE. Rio de Janeiro, RJ: Conselho Empresarial Brasileiro para o Desenvolvimento Sustentável.

LUIZ, A. J. B. Meta-análise: Definição, aplicações e sinergia com dados espaciais. Cadernos de Ciência \& Tecnologia, Brasília, v. 19, n. 3, p. 407- 428, set./dez., 2002. 
MACHADO-DA-SILVA, Clóvis L.; CUNHA, Vera C.; AMBONI, Nério. Organizações: o estado da arte da produção acadêmica. In: ENCONTRO ANUAL DA ASSOCIAÇÃO NACIONAL DOS PROGRAMAS DE PÓS-GRADUAÇÃO EM ADMINISTRAÇÃO, 14a., 1990. Florianópolis. Anais..Florianópolis, Anpad, 1990. Organizações. p 11-28.

PACHECO, Silvia R. Administração Pública nas revistas especializadas - Brasil, 1995 - 2002.São Paulo, Revista de Administração de Empresas N 4, Vol 43, p.63 a 71.

PEREIRA, M. C. A. Elementos de meta-análise. 1996. 65 p. Dissertação (Mestrado)Departamento de Estatística, Universidade de Brasília, Brasília.

RESPONSABILIDADE SOCIAL EMPRESARIAL: por que o guarda-chuva ficou pequeno? - São Paulo, SP: Aliança Capoava, 2010. p 9 a 11.

TONELlI, Maria José; CALDAS, Miguel; LACOMBE, Beatriz. B.M; TINOCO, Tatiana. Produção Acadêmica em Recursos Humanos no Brasil: 1991 - 2000. São Paulo, RAE No 1, Vol 43.

VERGARA, Sylvia C., PINTO, M. C. S. Nacionalidade das referências teóricas em análise organizacional: um estudo das nacionalidades dos autores referenciados na literatura brasileira. In: ENCONTRO NACIONAL DE ESTUDOS ORGANIZACIONAIS, 1a., 2000, Curitiba. Anais...Curitiba, 2000.

Data do recebimento do artigo: 30/3/2011 
Data do aceite de publicação: 23/11/2011

Revista de Gestão Social e Ambiental - RGSA, São Paulo, v. 5, n. 3, p. 36-52, set./dez. 2011. 